\title{
Need And Importance Of Medical Social Work Practice: Evidence, Challenges And Prospects With Special Reference To Karachi City
}

\author{
Sakina Riaz \\ Department of Social Work \\ University of Karachi
}

\begin{abstract}
This study briefly describes the history of this profession and also discusses the role of Medical Social Worker in Pakistani context. Furthermore, it also outlines some contemporary issues in this field. The paper is divided into three sections, section one provides a concise introduction of social work practices at global level, section two covers the history of the profession with special reference to Pakistani pedagogies. The succeeding portion covers the recommendation and concludes with some of the main structural, systemic, and professional challenges that remain and a call to action. An attempt has been made by the authors for in-depth analysis of the various aspects of existing practices; identify the problems and prospects of Medical Social Work with especial reference to Karachi, an urban city of Pakistan. This study is an exploratory research and the researcher has employed qualitative methods to explore this issue.
\end{abstract}

Keywords: Medical Social Work, Patient's Welfare, Health Care Institutions

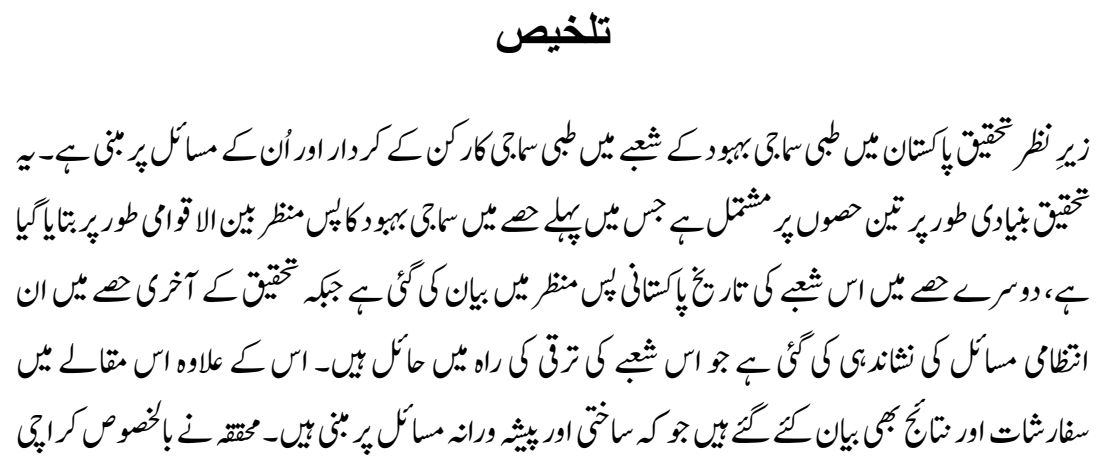




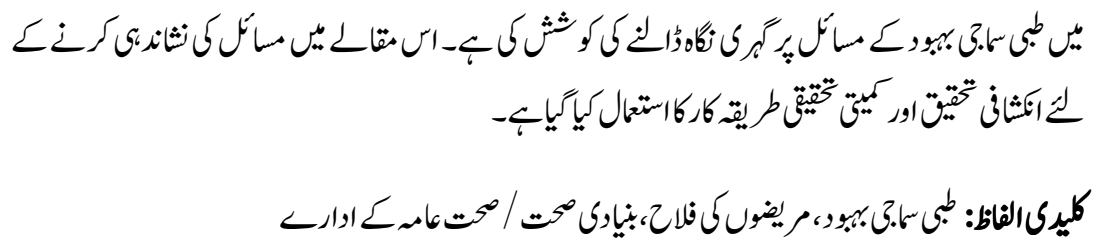

\section{Introduction}

Social Work is a professional discipline of global significance. It is all about working with people and seeing a person as a whole in the context of their current circumstances. Generally, social work is a profession for those with a strong desire to help people in improving their lives. Social work is an old discipline and has its unique combination of theory and filed practices. This uniqueness marks the profession as extra ordinary distension in the field of social sciences. This subject is purely based upon scientific knowledge and skills in human relations. Social workers respond to both crises and emergencies as well as always ready to provide help in everyday life of individual, group or community. The goal of social work is to lead the human beings into a successful life. However, the practice of social work consists of the professional application of social work values, based upon scientific knowledge, techniques for handling human behaviour. Social Workers use a variety of skills, techniques \& activities to assist individuals in making and sustaining positive change. As an adviser, advocate and counsellors a social worker helps people to live more successfully within their local communities by helping them find solutions to their problems.

Medical Social Work has been a very productive field; it is the branch of social work which deals the problems of patients in health care Institutions. Medical Social Workers are deputed in hospitals, mental health clinics for addressing the problems relevant to clinical practice. They as an expert; recognise that illness and admitting to hospital may have a direct impact on the psychological, social, and emotional well-being of the individual and his/her family. Medical Social Workers are trained in counselling and psycho-therapy to assist patients with health issues and problems with everyday life.

In this research paper, the researcher has made an endeavour to define the Medical Social Work philosophy and tried to relate with social caring obligation with cultural norms and value system of Pakistani people. The purpose of this qualitative study is two-fold: i) to review the development of Medical Social Work in Pakistan. In this context, historical growth of the profession in the country have been examined, and ii) to explore the need of Medical Social Work as a profession. A qualitative research strategy was adopted using participant observations in public hospitals of Karachi city. 


\section{Literature Review}

Social workers' involvement in medical inter-professional teams developed in the 1970s in England, and grew in popularity through the 1980s Ryan (2012). It has become a critical method in providing comprehensive care to patients Black (2005). Khalid (2001:301) and Malik \& Sarfaraz (2012:210) has pointed out the National Association of Social Workers USA definition in these words:

"Medical Social Work makes selected and extended use of those aspects of social works knowledge and methods which are particularly relevant to helping persons who have health and medical problems"

The historical growth of Medical Social Work in the world can be examined from following four major sources (Ali \& Rafi, 2013).

1. In the 1880, social work was started from England, that discharged patients of mental hospitals needed "after-care" in their homes in order to keep away from repetition of their illness. "Visitors" went to the patient's home and advised family and friends about the essential care of the patient.

2. In the 1890, the "lady almoners" in English hospitals had initiated the program in London by Sir Charles S. Loch, who emphasized on the importance of "volunteer receptionists".

3. "Visiting nurses" were the third foundation of Medical Social Workers. In 1883, Lillian Wald and Mary Brewster of the Henry Street Settlement House in New York began to visit the homes of sick people in the neighborhood, who were not in a position to pay for medical and nursing care. Some hospitals in New York learned from the experiences of the Henry Street Settlement House and they sent nurses from the hospital staff for "after-care" and supervision of discharged patients.

4. "Medical students" trained in social agencies, were the fourth foundation of Medical Social Work. Dr. Charles P. Emerson of Johns Hopkins University at Baltimore, in 1902, requested that his students serve as volunteers with charity agencies in order to gain an understanding of the influence of social, economic, and living conditions on the illness of patients.

There are numerous roles of Medical Social workers. Sheafor \& Horejsi (2006) writes that social workers have to play many roles within a workplace including a 
broker, advocate, teacher, counsellor, clinician, social change agent, and as a professional. The role of the Medical Social Worker is becoming increasingly complex. Some of the roles a Medical Social Worker performs in hospital setting include the role of educator, discharge planner, counsellor, case manager, assessor, and crisis intervention specialist Cowles \& Lefcowitz (1992); Herbert \& Levin (1996) found that Medical Social Workers, work in a variety of settings including inpatient hospital medical-surgical floors, hospital cardiac units, and emergency rooms. Medical Social Workers can also work in outpatient settings including renal, oncology offices and outpatient hospice (Fusenig, 2012).

Medical Social Workers are applying social case work methods in patient handling. When patients become his or her 'client' they do 'social diagnosis of patient problem. According to Marry Richmond (1917). whose work on this subject was considered as the Social Worker's bible for the years, she said:

"It is the attempt to arrive at as exact a definition as possible of the social situation and personality of the client". 1

There is a significance amount of literature available on the importance of social work, its fields and methods of practices; however, most of the researches are conducted in Western societies, for example Alston \& McKinnon (2005) perspectives, and another example of Cree (2010) who describes in her book about social work perspectives according to western societies. Centuries ago, the idea of welfare state began to influence the state policy and action, in most cases the state directly participates in the economic sphere, it controls and regulates wages, cost of living and prices, finances, credit, currency, foreign exchange, banking insurance, and several other matters are regulated and controlled for the benefit of common people Khalid (1982) and Shah (2015).

\section{Defying the Concept of Medical Social Work Practice in Pakistani Pedagogical Context}

Pakistan is a country situated in the Southern part of Asia is the $6^{\text {th }}$ most populous country of the World, with its current population estimated at 156.26 million (Government of Pakistan, 1998). Pakistan is a developing country with a rapidly growing population. Pakistan, with a GNP of US \$ 470 per capita, central government expenditure on health is only about 1\% (UNICEF, 1996). In the recent years, Pakistan has undergone enormous political, economical and social changes.

Medical Social Work has undergone considerable changes in Pakistan since its inception (1947). At that time, much of work was done upon the sponsorship, donations or aid basis of Philanthropists, Khalid (2011). History has witnessed the need of professionally organized social work services in the country since the inception of Pakistan. Medical Social Work services were initiated in the early 
time of newly independent country; there was a big target for government to rehabilitate the migrated people who were living in refugee camps in un-hygienic environment. Most of the time, the rehabilitation work has been done on haphazard manner without any proper planning for concrete or solid results. Rehmatullah (2002:288) has mentioned the growth of the discipline in Pakistan in her book, according to her:

"In 1953, Miss Anna Mo Toll, a Swedish, Medical Social Worker visited Karachi, in response to the request from the Govt. of Pakistan to UN".

In the early days of newly established country, everybody was perplexed about the meaning and scope of "Medical Social Work" and concerned about its scope or success in Pakistan. Some health officials even felt that there was no need to train people especially for Medical Social Work Rehmatullah (2002:290) and Malik \& Sarfaraz (2012:213). Medical Social Work started its journey in the decade of 1960s. It was started with the help of United Nations and Government of Pakistan. In 1953, a training programme in Medical Social Work was introduced under the joint support of Government of Pakistan and United Nations in Karachi (Khalid, 2006:282). First Medical Social Work was appointed at Tuberculosis Control and Training Centre in Karachi. Nowadays, approximately all the Public sector universities have the department of social work which offers field work training in medical setting as a compulsory subject in their master degree programmes. In the beginning, in Pakistan, the services of Medical Social Work were only limited to collect donation, charity or aid from eminent philanthropist of the society for the help of sick people and they also involved in rehabilitation of mahajiraeens. ${ }^{2}$ With the passage of time, the situation has changed drastically and Medical Social Work is no longer highly dependent on the philanthropist and volunteers for funding, it has become a profession now; although there is a strong alliance, which continues to exist in many cases. Currently, the social welfare services are operated through the provincial directorates of social welfare in the country in a systematic manner. There are about 90 Medical Social Work units in Punjab, 14 in Sindh, 1 in Baluchistan and 4 in Khyber Pakhtoon Khwa. In addition to the major government hospitals, several private hospitals and health related institutions have also employed Medical Social Work like Sindh Institute of Urology and transplantation (SIUT), Aga Khan University hospital (AKUH), The Kidney Center, and The Laybton Rehmatullah Trust for Blind and in Pakistan Eye Bank Society.

\section{Need and Importance of Medical Social Work in Pakistan and its Current Practices}

Social Workers in hospitals and medical centers, provide frontline services to patients with conditions spanning the entire health care continuum (NASW, 
2009). Medical Social Work offers services to all patients and their families; who are suffering from medical problems by facilitating all necessary services to make their lives easier, during their illness and help them to deal with the consequences directly related to that illness. Medical Social Workers are also facilitating the Patients in paper work, and provide guidance to the family through the entire process of Patient's admission, till they get discharged. They play an important role in linking-up the medical and social services in patient's speedy recovery and rehabilitation in the community. Due to work load, it is not possible for a doctor and nursing staff to solve patient's psycho-social or sometime economical problems. It is therefore, the Medical Social Worker, who plays a vital role in handling patient's needs effectively and efficiently.

In developing countries like Pakistan, the situation of professional social work, especially Medical Social Work is not in a better position. Although social work has been progressively recognized in some areas of Pakistan as a concept or as a profession, it is still felt by the masses as an act of 'good will' or charity inspired either by a sense of religious duty or simple piety.

The term 'Medical Social Work Practice' has been the subject of much debate in Pakistani pedagogy .It is tempting to argue that whether it is a profession or not? In fact, there is a lot of confusion over the use of the term -meaning and scope, still most of the people are not aware of the fact that it is a professional subject which is based on scientific knowledge. Medical Social Work grew out of humanitarian and democratic ideas, and its values are based on respect for equality, worth, and dignity of all people. It focused on meeting human needs and developing human potential by enabling them to solve their problem on self-help basis. This is extremely complex process, which demands a systematic approach for developing the understanding about the Patient rights and their satisfaction.

Globally, the scope of Medical Social Work education, remunerative work and community affairs is very demanding especially in developed countries. However, in Pakistan, the profession is yet to gain adequate recognition from those individuals and institutions that matter. This tragedy is the root cause in the fast growth of the profession in this country. History has witnessed that Pakistani people has a very rich tradition to help the patient visit them during their hospital. This practice is being considered as an important norm and moral obligation stems from Islamic ethical principles.

It is interesting to note that in Pakistan, social work as a profession perhaps partially misguided and has a less social status less as compare to any other scientific Profession. Moreover, there is a misconception among people that doctors, engineers are being considered as highly intellectual and credible profession. Most of the people believe that there is no need of any expertise, skills 
or professional degree is required for doing social work. Anybody can do the welfare work or distribute charity, or have the capacity to do development efforts can work as social worker or may be appointed, in any institution for performing the job of Social Welfare Officer or Medical Social Worker. In general, the common man perception is limited to this perception only. Ironically enough, in this modern era of technology, social changes seem to have motivated the situation as this filed have a lot of potential to change or improve human life.

In Pakistan, $3.1 \%$ of the gross domestic product is spent on economic, social, and community services; $43 \%$ is spent on debt servicing (Government of Pakistan, 2002). Public spending on health was $1 \%$ of GDP in 2013, which is lower than in Bangladesh (1.2\%) and Sri Lanka (1.4\%) (World Bank, 2015). In 2006, less than $17 \$$ was spent on each Pakistani's health, which is very low based on international standards (Poullier et al., 2003). Healthcare statistics shows that healthcare workers include 91,823 physicians, 37,623 nurses, 4,175 dentists, 22,528 paramedics, and 5,619 female health workers. There are 796 hospitals, 93,907 hospital beds, 5,171 basic health units, 531 rural health centers, and 856 maternity and child health centers (Government of Pakistan, 2001). The Pakistani healthcare system is neither competent nor comprehensive to provide adequate services for the growing population (Shariff, 2001).

Pakistan has under-went through a long socio-political conflict before and after 9/11 and even today, its citizens are facing great challenges that hinder in achieving socio-economic development. In Pakistan, most of the rural and urban people, live under poverty, are deprived from health services due to lack of doctors and nurses. People are still un-aware about healthy life style, and often their low economical background insists them to ignore the diseases at its early stage. Although, many efforts have been made to improve the health conditions of the people through availability of trained personnel, adequate supply of medicines and establishment of health services but still, there are a number of challenges existing in the way of progress, which requires a lot of work in the social development and progress of the country. Poverty, unemployment, unstable law and order or security condition, religious extremism and human trafficking, these are the great challenges that require social treatment immediately for the betterment of our society.

\section{Role of Medical Social Worker in Hospital Setting with Special Reference to Pakistan}

In Pakistan, the health sector suffers a lot in implementation of programmes effectively, due to in-sufficient funds availability in this field. In health sector less budget allocation is causing great difficulties to meet the needy patients' requirement. In Pakistan, due to rising cost of living is being increased rapidly; 
which leads to a number of social, emotional, psychological and economic problems. The situation becomes more serious if somebody from the family gets hospitalization due to any chronic illness.

In Pakistan, Medical Social Welfare is based on Patient Welfare Fund to cater the needs of poor patients. Medical Social Workers are appointed as Social Welfare Officers in government hospitals. Generally, they work with the help of hospital administration, doctors and eminent philanthropist, established Patient's welfare society in hospitals under the auspices of Medical Social Work Units, to support poor patients. The government also provides financial support from Zakat Fund ${ }^{3}$ and from Pakistan Bait-ul-Mal.

Historically, In Pakistan, professional social work owes its foundation to the first in-service training course sponsored by the Government of Pakistan Rehmatullah (2002) and now Medical Social Welfare Officers are employed in hospitals and clinics to provide timely psycho-social intervention to patients and their families and help them cope with, or solve problems arising from illness or disability. Medical Social Worker helps patients by explaining health-care resources and hospital policies to patients and their family and provides follow-up care or referral, if required. As a member in the multidisciplinary clinical team, they play an important role in linking-up the medical and social services to facilitate a patient's recovery and rehabilitation in the community. In hospitals, Social Workers focus not only on patients' medical care but also on community and environmental awareness as it impacts on patients' care. They recognize that poverty and lack of education could intensify illness. Because most of these disease conditions are preventable, social workers can handle them by the process of community organization.

A prime responsibility of Medical Social Worker in underdeveloped countries, like Pakistan, is to provide help and assistance to non- affording patients, who are not in a position to neither bear their medications nor have any health insurance coverage from any other sources. The main aim of this job is to help and facilitate poor patients by providing free medicines or making necessary arrangements for operations. They have to oversee patient's transition to nursing homes or in hospitals and facilitate them, if required. They also have to investigate assault and abuse cases for adults and children and report them appropriately.

Patient Education is another very important job of Social Welfare Officer. It is mainly focused on promoting health and good quality of life as well as informing the patient about what is happening to him or her, how it has affected, what are the doctors plans and how he has to adhere to treatment and also maintain a range of practice versatility, making hospital interventions fundamentally important for 
patients experiencing life-threatening illnesses or physically ill patients living within a hospital, especially with the increase in survival and recovery rates.

The Medical Social Worker has to play a critical role in the area of Patient's discharge planning from hospitals. It is the Medical Social Worker's responsibility to ensure all the services that a patient requires, are in-place. Some important services provided by Medical Social Worker includes psycho-social assessment of patient, coping, emotional and developmental capacities in the context of their social and environmental circumstances; provide counselling services through individual casework or group; working with families; crisis intervention; coordinate and collaborate with statutory and voluntary services regarding patients and their families; establish care links for referrals for community resources; aassessing child protection/elder abuse/domestic violence concerns and referring the patient's case at appropriate place; establishing the relationship between patient and doctor; provide information to the doctor about the social economic condition of patient so that doctor may be able to prescribe medicine in a better way; maintaining close collaboration with other medical and allied health professionals for psycho-social assessment and formulation of welfare plans; rehabilitate the patient in different ways i.e. providing free medicines, free medical assistance or financial assistance such as waiver of medical charges. They remain in touch with the patient through recreational / vocational trainings and provide them employment opportunities. In some cases making recommendations for charitable trust funds or arrange free medical treatment in case of deserving patients; provide free ambulance, collect blood donation and provide diet facilities to patients who cannot afford it. Medial Social Officer also works for the welfare of unknown and unattended patients, organized free medical camps within and outside of the Hospital for different communities. They also collects donations for deserving patients from different sources or from philanthropist ; works for the rehabilitation of disabled persons and their family members, in patient's rehabilitation and keeping in touch with the patients even after attaining health/physical treatment and pay home visits to the selected patients. Medical Social Workers have embarked on an ambition in celebration of national and religious days in the hospitals with the assistance and collaboration of hospital administration and patient's welfare society. They also involve in training of Social Case Work to the students of social work department of universities for their exposure of practical world. ${ }^{5}$

In Pakistan, like other developing or under developing countries, health care expenditure extends beyond the range of common man. The current political and economic climate has had a detrimental impact on some aspects of Medical social work practice. In fact, the importance of Medical Social Work as a profession and its role in patient care and in human welfare has become a sort of mantra, a mumand-apple -pie notion that few would provoke. 


\section{Challenges for Medical Social Services in Sindh}

Karachi is the largest city of Pakistan and provincial capital of Sindh Province .It the third largest city besides Istanbul and Shanghai in the whole world (Malik \& Wahid, 2014).

The discussion about need and importance of Medical Social Work practice in Karachi is closely related to the broader concept of social work development in Pakistan. There are lots of issues, which are disturbing the smooth running of the affairs of Medical Social Workers in Pakistan, generally and specifically in Sindh Province. Providing better healthcare facilities are the primary responsibility of any government.

Now, if we examine the current challenges of Medical Social Workers in the field, it is revealed that a number of non-financial constraints have played an equally important role in the under-performance of Social Welfare Officers working in the field. They are de-motivated and distracted from their work by conflicting interests; weak governance, shortage of human resource \& material resources (office, stationery ect), limited or lack of patient welfare funds, lack of opportunities for on-job training of Medical Social Officers, lack of coordination between Medical Social Worker and hospital Authorities, absence of social safety nets and lack of effective implementation of regulations are some of these factors having an adverse impact on the performance of Medical Social Worker in health care setting. Apart from the above problems, government of Pakistan has also invested less in this field, the practice of Medical Social Work or case work management is also in a disappointing situation. The government has also neglected this profession. Moreover, the social welfare training institutions does not performs it due role. It is need of the day to concentrate and establish social welfare projects in all districts across the country especially in all hospitals (both public and private) of Sindh Province.

In Pakistan, federal government and provincial government assumed overall responsibility for the implementation of health care services before the implementation of devolution plan of government of Pakistan. Through a process of decentralization initiated in August 2001, however, districts began to assume responsibility for all public activities, including health care services. The services of social welfare were also affected specially for those Medical Social Workers who works under the control of federal government. Consequent upon approval of $18^{\text {th }}$ Amendment Act, government of Pakistan (2010) in the constitution of Islamic Republic of Pakistan, resultant abolition of concurrent legislative list and thereby devolution of Social Services ( in medical setting); the services of officers under the Ministry of Social Welfare \& Special Education has been transferred to 
the Social Welfare Department Government of the Sindh vide Establishment Division Government of Pakistan Notification No .4-5/2011 dated $5^{\text {th }}$ April 2011 (Govt. of Pakistan Notification, 2011). Following are the details of institutions where the services of Medical Social Welfare Officers have been transferred:

1. Social Services Medical Centre, National Institute of Child Health (NICH), Karachi.

2. Social Services Medical Centre, National Institute of Cardiac Vascular Diseases (NICVD) ,Karachi.

3. Social Services Medical Centre, Jinnah Post Graduate Medical Centre (JPMC), Karachi.

After implementing the devolution plan, there have been many issues and difficulties, which arise in the Medical Social Work practice in Sindh and directly related with their job placement of Medical Social Welfare Officers and this situation caused the great impact on their performance. After the transfer of Medical Project to sindh government a number of issues grow up in social welfare administration department. Firstly, in the province of sindh, a ban has been imposed by the provincial government to on hiring or fresh appointment of any Medical Social Welfare Officers in hospital due to government shortage of funds. Secondly, those who are transferred from federal government to the govt. of Sindh without any financial incentives are highly de-motivated as there is no job career progress for them. They continue their job till there retirement without having any training or further promotion in their jobs. Thirdly, in the province of Sindh, Medical Social Officers in provincial level are offering their services in few hospitals. In Karachi, in government hospital set up, social welfare services are providing only in Jinnah Post Graduate Medical Centre, which is a Federal Administrated Hospital. The provincial administrated hospitals like civil hospital, the Medical Social Welfare projects are not functional due to shortage of resources. Few hospitals that are running in private setup are being providing the Medical Social Welfare services in Karachi (like the Aga Khan Hospital) where the non-qualified Social Welfare Officers are employed to cater the need of poor and vulnerable patients in the hospital.

Currently, the job of Social Welfare Officer in hospitals has led to a decrease in formal opportunities for practice in Sindh, a province of Pakistan, and as a result MSO has led to feelings of isolation, loss of professional identity, lack of funds availability, lack of training opportunities for them and low morale among the social workers, students of social work who belongs to Karachi and Sindh .This issue is very complex and multidimensional, requiring immediate response as it directly impact on professional growth of social work practice in this province and also creates a lot of jobless and frustrated employees in this field. 


\section{Recommendations}

This study recommends that professional social workers should strive to work for continuation of the jobs and fresh appointment of Medical Social Work in Sindh province as it is practiced in other provinces of Pakistan. There is a great need to appoint social workers in different hospitals (in both public \& private sector) in order to improve the quality of services for patients and well-being of Pakistan's population.

Moving the Medical Social Work profession into the mainstream of healthcare delivery in Pakistan requires immense efforts on many fronts. There is a dire need to change the public image for meaningful and flourishing growth of the profession in the country, it is suggested that the modification in job identification may be done and the term of Medical Social Work may be replaced as" Medical Social Work practitioner".

This paper specially recommends that the governments of Pakistan should formulate a clear vision and appoints Medical Social Workers in public hospitals across Sindh Province (in each District).Beside this, government may implement a unanimous procedure in entire country as the other provinces of Pakistan like Punjab, KPK and Baluchistan have appointed Medical Social Workers and their Project are running properly.

This study also indicates many significant barriers to the growth of Social Work in the field of health care in the Sindh Province, therefore, it is suggested to reshape the existing employment structure and design better policies for future. In this era of modernization, professional training of MSO at national and international level is also required. The federal Ministry of Health and the Provincial Department of Health and Ministry of Social Welfare have to play a critical role and procedural fairness has to be taken in this respect.

Furthermore, in order to eliminate the non -professional working in health care set-up as medical social worker, effective efforts are required for licensing of Medical Social Workers. More importantly, association of social workers is still not establish which is milieu to operate or functional for professional identity in the country.

\section{Conclusions}

In conclusion, this study suggests that Medical Social Workers are a valuable member of the interdisciplinary team in health care setting, fulfilling multiple roles for the well-being of patients. In pursuance of new possibilities for a better world, it is important that state empower social sciences especially social work as 
profession by integrating policies and practices that support and nurtures' social work perspectives, and approaches. Finally, government especially ministry of social welfare, civil society, pioneer social worker practitioners should move towards up-gradation of Medical Social Work Services in all the districts' of Sindh Province.

\section{Notes}

1 In 1917 Mary Richmond writes one of the defining books of social work, Social Diagnosis, in which she lays the foundation for social work as a profession with a mission. Source: https://us.sagepub.com/sites/default/files/ upm-binaries/38142_Chapter2.pdf, p.39, retrieved on $17^{\text {th }}$ September, 2015.

2. In this article the word 'Mahajireen' refers for those people who migrated from India to Pakistan in 1947.

3. Zakat is a Religious Tax, lived on every Muslim Voluntarily paid by an individual to those found in need.

4. Pakistan Bait-ul -Mal System (PBM) fulfills the aims and objectives of an Islamic Welfare State based on purely Islamic Tenants. In, Pakistan, in 1992 the Government set up Bait-ul-Mal, established as a separate body, a fund to provide assistance for the needy and destitute persons.

5. Based on author's knowledge and experience. The author had an experience as a medical social worker for almost a decade in a hospital in Karachi city.

\section{References}

Ali, Mumtaz \& Rafi, Sadia (2013). Medical Social Work in Pakistan: a MultiModel Approach to Collaborative Practice in Health Care Settings Academic Research International Part-II: Social Sciences and Humanities, vol.4, pp.335-363. http://www.savap.org.pk, Access on 23 ${ }^{\text {rd }}$ August, 2015.

Alston Margaret, McKinnon Jennifer (2005). Social Work Field of Practice, Singapore: Oxford University Press, Melbourne, VIC

Ather H. Akbari, Wimal Rankaduwa, and Adiqa k. Kiani (2009) Demand for Public Health Care in Pakistan, The Pakistan Development Review, vol.48:2, pp.141-153.

Black, K. (2005). Advance Directive Communication Practices: Social Workers' Contributions to the Interdisciplinary Health Care Team, Social Work in Health Care, vol.40:3, pp.39-51 
Bradford W. Sheafor and Charles R. Horejsi, (2006). Techniques and Guidelines for Social Work Practice, $\left(8^{\text {th }}\right.$ ed). USA: McGraw Hill. http://www.ums.edu.my/ fpp/images/prospektus/spks_eng.pdf, retrieved on $15^{\text {th }}$ Sept, 2015

Britta E. Ryan (2012). A Qualitative Study of Medical Social Workers' and Nurses' Perceptions on Effective Inter Professional Collaboration, MSW Clinical Research Paper, School of Social Work, St. Catherine University. http://sophia.stkate.edu/cgi/viewcontent.cgi?article=1084\&context=msw_ papers, retrieved on $15^{\text {th }}$ Sept, 2015

Cowles L.A. \& Lefcowitz MJ. (1992). Interdisciplinary Expectations of the Medical Social Work in the Hospital Setting: Part 2, Health and Social Work, vol.20:4, pp.279-287.

Cree, Vivien E. (2010). Sociology for Social Workers and Probation officers $\left(2^{\text {nd }}\right.$ edition) New York, Routledge.

Cree, Vivienne E. (2010) Social Work; A Reader, London, Routledge.

Fusenig, Elizabeth (2012). The Role of Emergency Room Social Worker: An Exploratory Study, Master of Social Work Clinical Research Papers 26, School of Social Work, St. Catherine University, http://sophia.stkate.edu/ msw_papers/26, retrieved on $15^{\text {th }}$ Sept, 2015

Government of Pakistan. (1998-2003). Planning and Development Division, Population Projections of Pakistan.

Government of Pakistan. (2001). Ministry of Health, An Overview of the Health Sector: The Way Forward. Islamabad, Pakistan: Multi Donor Support Unit; 20

Government of Pakistan. (2002). Ministry of Finance, Budget 2001-2002. Pakistan, Finance Division.

Government of Pakistan. (2009). PSLM- 2004-05, 2007-08-Pakistan Social and Living Standards Management Survey, Islamabad: Federal Bureau of Statistics.

Government of Pakistan. (2010). Act No.X of 2010.

Government of Pakistan. (2012). Economic Survey of Pakistan (ESP), Ministry of Finance, 2011-12. 
Herbert \& Levin, (1996). Herbert M, Levin R. Social Work in Health Care. vol.22:3, pp.71-83. PMID:8724846, retrieved on 24-6-2015, http://www.tandfonline. com/doi/abs/10.1300/J010v22n03_05

Hobbs, M. (2005). The Social Worker on the Medical Interdisciplinary Team, Journal of Health Care for the Poor and Underserved, vol.16:2, pp.186-191.

Khalid, Muhammad (1982). The Study of Social Work in Pakistan, Karachi, Kifayat Academy, pp.1-13.

Khalid, Muhammad (2001). Social Work Theory and Practice: with Special Reference to Pakistan, $3^{\text {rd }}$ Edition, Kifayat Academy, p.301.

Khalid, Muhammad (2006). Social Work Theory and Practice: with Special Reference to Pakistan, $4^{\text {th }}$ Edition, Kifayat Academy, p. 282.

Khalid, Muhammad (2011). Social Work Theory and Practice: with Special Reference to Pakistan, $7^{\text {th }}$ Edition, Kifayat Academy, pp.34-36.

Khurshid Khowaja (2009). International Perspectives: Healthcare Systems and Care Delivery in Pakistan, Journal of Nursing Administration, vol.39:6, pp.263-265, http://nursingcenter.com/journalarticle?Article_ID=865859.

Malik, A. \& Sarfaraz, F. (2012). Social Work Practice in Health Care with Special Reference to Pakistan, Pakistan Journal of Commerce and Social Science, vol.6:1, p.210.

Malik, A. \& Sarfaraz, F. (2012). Social Work Practice in Health Care with Special Reference to Pakistan, Pakistan Journal of Commerce and Social Science, vol. 6:1, pp.210-215

Morley D.Glicken (2007). Social Work in the $21^{\text {st }}$ Century: An Introduction to Social Welfare, Social Issues, and the Profession, Sage Publications, Inc. California, United State of America, p.33.

National Association of Social Workers. (2005). Standard for Social Work Practice in Health Care Settings, Washington DC: NASW.

National Association of Social Workers, Center for Workforce Studies, (2009). Social Workers in Hospitals and Medical Centers, Occupational Profile, Washington, DC, NASW, http://workforce.socialworker.org/Studies/profiles/Hospitals.pdf, accessed on $4^{\text {th }}$ September, 2015 
Poullier J.P, Hernandez P., Kawabata K., Saved off W.D., (2002). Patterns of Global Health Expenditures: Results for 191 Countries, EIP Discussion Paper No. 51, Geneva, Switzerland: World Health Organization. http://www.who.int/healthinfo/paper51.pdf, access on $9^{\text {th }}$ Sept, 2015

Rehmatullah, Shireen (2002). Social Welfare in Pakistan, London, Oxford University Press, p.1.

Rehmatullah, Shireen (2002). Social Welfare in Pakistan, London, Oxford University Press, p.288.

Richmond, Mary (1917). Social Diagnosis, Russell Sage Foundation, New York, p.62.

S., Siddiqi, S., Hamid, G., Rafique, S., A. Chaudhry, N., Ali, S., Shahab \& R., Sauerbon (2002). Perception Practices of Public and Private Health Care Providers in Attock District of Pakistan, International Journal of Planning and Management, vol.17, pp.23-40.

Sana, Malik \& Julaihi, Wahid (2014). Rapid Urbanization: Problems and Challenges for Adequate Housing in Pakistan, Journal of Sociology and Social Work, vol.2:2, pp.87-110

Sanjay, Bhattacharya (2008). Social Work Psycho-Social and Health Aspects, Deep \& Deep Publication (p)Ltd., New Dehli, India. p.1.

Shah, N.A. (2015). Social Work Teaching in Pakistan Problems and Remedies, New Horizons, vol.9, p.98.

Shariff, K.M. (2001). Pakistan Almanac 2001-2002, Essential Data on Pakistan, Pakistan, Royal Book Company, pp.201-213.

Sheafor, B.W. \& Horejsi, C.R. (2006). Techniques and Guidelines for Social Work Practice, Pearson; ( $9^{\text {th }}$ ed.), ISBN-10: 0205838758

UNICEF. (1996). The State of the World Children 1996. Bellamy C eds. Oxford University Press.

World Bank. (1998). Raising a Healthier Population, South Asia Brief, vol.27:1, pp.49-54.

World Bank. (2015). Pakistan Overview, Washington DC, http://www.worldbank. org/en/country/pakistan/overview. 
Dr. Sakina Riaz is Assistant Professor in the Department of Social Work, University of Karachi. 